\title{
Promoção da saúde: análise da atuação do poder Legislativo municipal
}

\author{
Talita Santos Borges Nascimento $^{1}$; Tatiane de Oliveira Silva Alencar ${ }^{2}$ \\ 1. Bolsista FAPESB/CNPq, Graduando em Farmácia, Universidade Estadual de Feira de Santana, e-mail: \\ talita_sbn@hotmail.com \\ 2. Orientador, Departamento de saúde, Universidade Estadual de Feira de Santana, e-mail: \\ tatifarmauefs@yahoo.com.br
}

PALAVRAS-CHAVE: Promoção da Saúde; Saúde pública; Políticas públicas.

\section{INTRODUÇÃO}

As políticas públicas no âmbito da saúde são elaboradas com o intuito de melhorar as condições de saúde da população e dos ambientes sociais, natural e de trabalho. Consiste em organizar as funções públicas governamentais para a promoção, proteção e recuperação da saúde dos indivíduos e da coletividade. As políticas públicas de saúde voltadas para a promoção da saúde são direcionadas a toda população, não sendo específica a uma doença ou grupo de risco (BUSS, 2010; LUCCHESE, 2004).

É o Poder Legislativo que formula as políticas públicas, sendo composto por membros eleitos pelo povo para exercer função, dentre outras, de legislar. O papel desempenhado pelo Legislativo na condução de determinadas políticas públicas é decisivo, pois representa a legitimação, o controle político, a fiscalização e a vigilância sobre a atividade governamental e canal de comunicação entre os que detêm o poder político e o povo (TORRENS, 2013; TESTON, 2015).

No Brasil, os princípios e ações de promoção da saúde foram referenciados na Carta de Ottawa para a implantação no Sistema Único de Saúde (SUS) através do movimento da Reforma Sanitária. No entanto somente em 30 de março de 2006 o Ministério da Saúde aprovou a Política Nacional de Promoção da Saúde por meio da Portaria $n^{\circ}$ 687, tendo como objetivo promover a qualidade de vida e reduzir os riscos à saúde relacionados aos modos de vida, condições de trabalho, habitação, ambiente, educação, lazer, cultura, acesso a bens e serviços essenciais.

Este trabalho teve como objetivo, portanto analisar as disposições legais relativas à saúde elaboradas pelo poder Legislativo de um município baiano, entre janeiro de 2016 e dezembro de 2017, com o intuito de discutir em que medidas tais políticas podem implicar na promoção da saúde.

\section{METODOLOGIA}

Para a produção dos dados foi utilizada a técnica de análise documental. A coleta de dados foi realizada no site da Câmara Municipal de Vereadores de Feira de Santana - BA, 
utilizando o descritor "saúde", e como filtro da pesquisa as disposições legais (projetos de leis) referentes ao período de 01/01/2016 a 31/12/2017 e que ainda estejam vigentes.

\section{RESULTADOS E/OU DISCUSSÃO}

Foram encontradas 24 leis municipais entre o período de janeiro de 2016 à dezembro de 2017, sendo quatro em 2016 e vinte em 2017. Do total das proposições, 19 foram de vereadores e cinco do Poder Executivo. As vinculações partidárias foram: dois do Partido Social Cristão (PSC), dois do Partido Democrata (DEM), um do Partido Verde (PV), um do Partido Republicano Brasileiro (PRB), um do Partido Pátria Livre (PPL), um do Partido Republicano Progressista (PRP) e um do Partido Trabalhista Cristão (PTC).

No geral, os propositores vereadores apresentam o seguinte perfil: idade entre 30 a 55 anos, a maioria com naturalidade de Feira de Santana-Ba, dois no município de Salvador -Ba e apenas um nascido fora do estado da Bahia.

Do total de nove propositores, cinco estão no seu primeiro mandato, dois estão no terceiro, um no quarto e um no sétimo mandato como vereador do município.

Em relação ao grau de escolaridade, a carcaterização foi a seguinte: três com ensino médio completo, um nível técnico e cinco possuem ensino superior com formação em Geografia, Nutrição, Direito, Serviço Social e Gestão em recursos humanos.

No geral, os temas constantes nas disposições foram assim categorizados: educação em saúde, modos de vida, acesso a bens e serviços essenciais e ambiente. $\mathrm{O}$ tema mais abordado nas legislações foi educação em saúde, presente em 15 disposições; seguido por modos de vida em três disposições; ambiente, em duas disposições legais; e acesso a bens e serviços essenciais em sete.

No que diz respeito às disposições encontradas sobre educação em saúde, compreendemos que há um direcionamento para ações visando a conscientização e a disseminação de informações relativas a determinados assuntos de saúde: saúde mental; gravidez e pós-parto; nascituros e crianças na primeira infância; doação de sangue e medula óssea; e doenças sexualmente transmissíveis. Nestas disposições há foco para responsabilização dos gestores municipais, principalmente das Secretarias Municipais de Saúde e Educação, no cumprimento das ações sem, contudo, deixar claro a responsabilidade dos profissionais de saúde e das unidades de saúde nesse processo.

O Ministério da Saúde trata a educação em saúde como um processo de construção educativo de conhecimento em saúde que tem como objetivo permitir que a população se aproprie dos assuntos referentes a sua saúde. Esse processo envolve três protagonistas sociais: os profissionais de saúde, que são os agentes envolvidos na prevenção de danos e na promoção do cuidado e da saúde; os gestores, responsáveis por apoiar e dar condições para que os profissionais de saúde cumpram seu papel; e a população que necessita construir seus 
conhecimentos e aumentar sua autonomia nos cuidados, individual e coletivamente (BRASIL, 2006; FALKENBERG et al., 2014).

As disposições que abordam modos de vida trazem no seu texto abordagens e ações sobre acometimentos de saúde que interferem nas relações sociais e na inserção social de populações específicas no cenário cotidiano. Essas legislações abordam os direitos desses grupos, a prevenção de determinados acometimentos de saúde que são reflexos de situação social, ambiente inserido, educação e contexto econômico desses indivíduos. Além disso destacam programas de inserção social, de recuperação e de informação sobre direitos dos cidadãos como meios de intervenção do modo de vida dessas pessoas para que assim promovam saúde e qualidade de vida.

Nas disposições sobre ambiente, são considerados aspectos de intervenções no âmbito da gestão que interferem no meio ambiente e nas condições ambientais de moradia da população que são condicionantes do estado de saúde/adoecimento coletivo.

A promoção da saúde se refere às ações sobre os condicionantes e determinantes sociais da saúde, ou seja, nas diferenças nas condições e oportunidades de vida dirigidas a impactar favoravelmente a qualidade de vida. Então, para promover a saúde, é preciso enfrentar esses então chamados determinantes sociais da saúde na busca da construção de espaços saudáveis. Por isso, caracterizam-se fundamentalmente por uma composição intersetorial e, intrasetorialmente, pelas ações de ampliação da consciência sanitária - direitos e deveres da cidadania, educação para a saúde, estilos de vida e aspectos comportamentais etc (BRASIL, 2010; SíCOLI et al., 2003).

Referente ao tema do acesso a bens e serviços essenciais foram encontradas disposições com potencial para promoção do acesso, principalmente a serviços de saúde a populações específicas que são alvo de vulnerabilidade social; algum tipo de deficiência, ou que sofrem com exclusão social; grupos acometidos por doenças que necessitam de atendimento em especialidades. Tais disposições visam tornar prioritário o atendimento desses grupos populacionais, bem como da viabilidade estrutural para proporcionar acesso às unidades de saúde e hospitais para pessoas com deficiência.

Como afirmado na Carta de Ottawa, a promoção tem como objetivo garantir o acesso a todos os bens e serviços essenciais, que é tudo aquilo que é indispensável e inerente a qualidade de vida e estado de saúde da população. No que diz respeito a acesso universal a saúde está relacionado com o princípio de equidade. Segundo a OMS, para alcançar a equidade é preciso reorientar os serviços sanitários, visando ampliar o acesso, e criar ambientes de suporte, com políticas que viabilizem condições de vida favoráveis à saúde, priorizem grupos desprivilegiados e vulneráveis, e revertam as desigualdades sociais instaladas na busca de melhor qualidade de vida e saúde para estas pessoas (BRASIL, 2000; BUSS, 2010).

A partir destas disposições legais analisadas podemos identificar que os gestores propositores do município de Feira de Santana- BA têm, na sua maioria, focado sua atenção em 
leis que busquem a conscientização a disseminação de informações com potencial de impactos na qualidade de vida e promoção da saúde. No entanto, não foram visualizadas estratégias para operacionalizar tais ações, nem mesmo no que se refere à divulgação das muitas campanhas propostas nas leis municipais. Isso evidencia que há uma lacuna importante entre as proposições legais e suas implicações nos serviços e na vida dos cidadãos.

\section{CONSIDERAÇÕES FINAIS}

Constatou-se que os propositores das políticas de saúde municipais, do período janeiro de 2016 a dezembro de 2017, em sua maioria, não têm vinculações diretas com a área da saúde. De outro lado, foi encontrado um volume considerável de legislações que trazem como abordagem o tema central da saúde nos subtemas educação e saúde, modos de vida, ambiente e acesso a bens e serviços essenciais. Ressalta-se, porém, que tais disposições não necessariamente têm implicado na resolubilidade das ações e promoção da saúde dos cidadãos, e nem mesmo estão claras as estratégias para sua execução.

\section{REFERÊNCIAS}

BRASIL. Ministério da Saúde. Sistema Único de Saúde (SUS): princípios e conquistas. Secretaria Executiva, Brasília: MS, 2000.

BRASIL. Ministério da Saúde. Secretaria de Gestão do Trabalho e da Educação na Saúde. Departamento de Gestão e da Regulação do Trabalho em Saúde. Câmara de Regulação do Trabalho em Saúde. Brasília: MS; 2006.

BRASIL. Ministério da Saúde. Secretaria de Vigilância em Saúde. Secretaria de Atenção à Saúde. Política Nacional de Promoção da Saúde. Secretaria de Atenção à Saúde. - 3. ed. Brasília: Ministério da Saúde, 2010.

BUSS, P. M. O conceito de promoção da saúde e os determinantes sociais. Bio-Manguinos: Rio de Janeiro, fev. 2010.

FALKENBERG, M. B. et al. Educação em saúde e educação na saúde: conceitos e implicações para a saúde coletiva. Ciência \& Saúde Coletiva, v. 19, n. 3, 2014, p. 847-852.

LUCCHESE, P. T. R. (coord.). Políticas públicas em Saúde Pública. São Paulo: BIREME/OPAS/OMS, 2004.

SÍCOLI, J. L.; NASCIMENTO, P. R. Promoção de saúde: concepções, princípios e operacionalização. Interface - Comunic, Saúde, Educ, v.7, n.12, 2003, p.91-112.

TESTON, L. M. Legislação em saúde: um estudo sobre a iniciativa de projetos de lei no estado do Acre. Rev. Dir. sanit., São Paulo v.16 n.1, mar./jun. 2015, p. 19-38.

TORRENS, A. C. Poder Legislativo e políticas públicas: uma abordagem preliminar. Rev. de Informação Legislativa, Paraná, n. 197, jan./mar. 2013. 